\title{
Effect of post-reward confinement on choice behavior'
}

JAMES BOWEN

Twenty rats learned a position preference in a $T$ maze. The Ss were then matched and divided into two groups. Group $C$ received two free and two forced choices daily so that each $S$ entered both sides equally often and received $10 \mathrm{sec}$. reward regardless of the side entered. Group PRS received the same treatment except that if a $S$ chose the side opposite to which it had been trained, it received a $30 \mathrm{sec}$. goal box confinement following the reward. On free choice trials, Group C chose the side opposite to which it had been trained significantly more times than Group PRC.

In experiments aimed at determining the effect of post-reinforcement confinement (PRC) on resistance to extinction, both Fehrer (1956) and Cogan (1966) report that there were no acquisition differences between PRC and non-PRC groups. These results seem pertinent to contiguity theories such as Spence's (1956). Presumably, competing responses would occur during PRC, become conditioned to goal box stimuli, and tend to occur in the alley through stimulus generalization. Such a series of events should result in a weaker effective reaction potential for the PRC group by increasing inhibition $\left(I_{t}\right)$. Since the results cited above are at least mildly significant theoretically, it was felt that a more sensitive design should be tried before accepting the null hypothesis.

Method

The Ss were 20 experimentally naive Wistar strain albino rats approximately 90 days old at the beginning of training.

The apparatus was an enclosed wooden $T$ maze, 4 in. wide, 5 in. deep, and covered with hinged hardware cloth. The floor of the maze was also constructed of hardware cloth. The stem of the maze was 36 in. long, the arms were 16 in. long. The entire apparatus was painted a mid-gray. Tin feeding cups 2 in. $x 2$ in. $x 2$ in. were fastened at the end of eacharm and so constructed that they could be pulled back flush with the wall and thus prevent access to any food inside. Guillotine-type doors placed at the entrance to the arms prevented retracing.

The Ss were accustomed to a food deprivation schedule for 10 days. During the first eight days, the Ss were handled in groups of 10 for $1 / 2 \mathrm{hr}$. and then fed wet mash for $1 \mathrm{hr}$. in their home cages. On days 9 and 10 Ss explored the maze in groups of four for $15 \mathrm{~min}$. each. The Ss were then randomly divided into two groups of 10. On Day 11, experimental training began. During Phase $I$, one group was trained to turn right in the maze, the other left, at five trials per day, until all five choices on any day were correct. The reward was $10 \mathrm{sec}$. access to wet mash. Confinement after incorrect choices was also $10 \mathrm{sec}$. The Ss within each group were then divided into matched pairs with the matching done on the basis of the number of errors made in reaching criterion. In Phase II, each S received four trials daily for 18 days. The first two trials were free choices, the last two forced, so that each $S$ entered each arm twice each day. One $S$ of each pair received $10 \mathrm{sec}$. reward no matter which way it turned (Group $\mathrm{C}$ ). The other $\mathrm{S}$ of each pair received $10 \mathrm{sec}$. reward for turning the way it was trained to turn in Phase I, and $10 \mathrm{sec}$. reward followed by $30 \mathrm{sec}$. PRC for turning the opposite way. If a $\mathrm{S}$ in Group $\mathrm{C}$ chose the side opposite to which it had been trained, the food cup was pulled flush with the wall after the $10 \mathrm{sec}$. reward period and $S$ was removed immediately. PRC was given by leaving $S$ in the goal box for $30 \mathrm{sec}$. after the food cup was pulled flush.

\section{Results and Discussion}

Each S's score was the number of times out of the 36 free choices that it chose the side opposite to which it had been trained. The mean for Group PRC was 7.5 , for Group $C, 12.7$. The difference was significant $(F=8.4, d f=1 / 9, p<.025)$. The differences between matched pairs were just short of significance $(F=3.14$, $\mathrm{df}=9 / 9, \mathrm{p}<.10$ ).

The groups appeared to be approaching different asymptotes. The probability of choosing the side opposite the trained side on the last four free choices was $\mathbf{. 5 0}$ for Group C and .31 for Group PRC. These values appeared to be asymptotic.

The results, then, seem fairly straightforward. With magnitude of reward held constant, the Ss had a bias against PRC which is consonant with Spence (1956). The effect of PRC seems reasonably weak, however. In addition to the failure of others to obtain a difference, PRC accounted for only 18 percent of the variance in the present study $(\mathrm{E}=.43)$.

\section{References}

Cogan, Dennis C. Post-reinforcement delay in extinction: a failure to replicate. Paper read at Midwestern Psychological Associati on Convention, Chicago, May, 1966.

Fehrer, E. Effects of reinforcement and of pre- and post-reinforcement delays on learning and extinction. J. exp. Psychol., 1965, $52,167-176$

Spence, K. W. Behavior theory and conditioning. New Haven: Yale University Press, 1956.

\section{Note}

1. This research was supported in part by Public Health Service Research Grant MH 10041-01 from the National Institute of Mental Health. 